\title{
Physioelectrochemical Investigation of Electrocatalytic Activity of Modified Carbon Paste Electrode in Alcohol Oxidation as Anode in Fuel Cell
}

\author{
Javad Shabani-Shayeh ${ }^{1 *}$, Ali Ehsani ${ }^{2}$, and Majid Jafarian ${ }^{1}$ \\ ${ }^{I}$ Department of Chemistry, Faculty of science, K. N. Toosi University of Technology, Tehran, Iran \\ ${ }^{2}$ Department of Chemistry, Faculty of science, University of Qom, Qom, Iran
}

(Received March 10, 2014 : Accepted July 17, 2014)

\begin{abstract}
Methanol electro oxidation on the surface of carbon paste modified by $\mathrm{NiCl}_{2} / 6 \mathrm{H}_{2} \mathrm{O}$ was studied in $1 \mathrm{M} \mathrm{NaOH}$ by potentiostatic and potentiodynamic methods. $\mathrm{Ni} / \mathrm{C}$ catalyst by the concentration of $5 \% \mathrm{Ni}$ showed about twice higher electro catalytic activity than $\mathrm{Ni}$ metal. The amount of monolayer's on the surface of electrode is almost one order higher for $\mathrm{Ni} / \mathrm{C}$ than Ni electrode. The kinetic parameters and the diffusion coefficient of methanol were derived from chronoamperometry (CA) and electrochemical impedance spectroscopy (EIS) measurements.
\end{abstract}

Keywords : Methanol electro-oxidation, carbon paste, impedance, modified electrode.

\section{Introduction}

The increasing demand for higher quality, higher density power supplies with better time performance is one of the principle reasons that growth in the portable power production market is expected. ${ }^{1)}$ Telecommunications, computers and the internet have already become practically essential for modern human life. There is a growing market for fuel cells on mobile phones, laptops and other portable electric devices. Vehicular applications using fuel cells as a source of energy have also attracted considerable interest. ${ }^{2)}$

Direct methanol fuel cell is regarded a potential candidate for power generation in electric vehicles. This stems from the facts that methanol is a relatively high energy density fuel, liquid at ambient temperature, low cost and available at industrial scale, the infrastructures for production and distribution are already available. ${ }^{3-12)}$ One of the impeding problems in the commercialization is perhaps the high over-potential associated with the direct elec-

*E-mail: Shabanijavad75@gmail.com tro-oxidation of methanol. Although electro-catalysts based on $\mathrm{Pt}^{13)}$ and $\mathrm{Pt}-\mathrm{Ru}$ alloys ${ }^{14,15)}$ have been developed and indeed exhibit good activities, high costs of these materials are often very prohibitive. A great deal of interest has recently been centered on the materials immobilized on to the electrode surface and capable of mediating fast electron transfer from methanol, namely its electro-oxidation. ${ }^{6-7)}$ Nickel is a suitable metal for electro catalysis in alkaline media because of its low cost and abundance. ${ }^{16)}$ Many types of catalysts containing nickel have been suggested e.g. Ni metal, ${ }^{17)}$ nickel complexes, ${ }^{18)}$ polymer with nickel incorporated electrode $^{19-20)}$ also Many works have been carried out on $\mathrm{CPE} \mathrm{Ni.}{ }^{21)}$ Taraszewska and Roslonek ${ }^{22)}$ found that $\mathrm{Ni}(\mathrm{OH})_{2}$ modified glassy carbon electrode acts as an effective catalyst for the oxidation of methanol. Van Effen and Evans ${ }^{23)}$ found that the oxidation of ethanol on $\mathrm{Ni}$ in $\mathrm{KOH}$ solution involved the formation of a higher valent nickel oxide, which acts as a chemical oxidizing agent. This fact was confirmed by both cyclic voltammetry and impedance spectroscopy. ${ }^{24)}$ Fleischmann suggested a three step for oxidation of nickel in alkaline media. ${ }^{25)}$ 
The purpose of the work is to present a new method for provide carbon paste modified with nickel chloride (NCMCPE) due to its low cost, ease of preparation, very high stability and study the electro-chemical oxidation of methanol on modified electrode aiming at the elucidation of the mechanism, derivation of the kinetic parameters of the process and the viability of the electro-catalytic process.

\section{Experimental}

\subsection{The chemicals}

$\mathrm{NiCl}_{2} \cdot 6 \mathrm{H}_{2} \mathrm{O}$, sodium hydroxide, graphite, and methanol, used in this work were Merck products of analytical grade and were used without further purification. Double distilled water was used throughout.

\subsection{The cell and instruments}

Electrochemical studies were carried out in a conventional three electrode cell powered by an electrochemical system comprising of EG\&G model 273 potentiostat/galvanostatand Solartron model 1255 frequency response analyzer. The system is run by a PC through M270 and zplot/zview commercial software via GPIB interface. The frequency range of $100 \mathrm{kHz}$ to $10 \mathrm{mHz}$ and the modulation amplitude of $10 \mathrm{mV}$ were employed for impedance studies. A dual $\mathrm{Ag}-\mathrm{AgCl}$ saturated $\mathrm{KCl}$ and a $\mathrm{Pt}$ wire electrode were used as the reference, and counter electrodes, respectively. All studies were carried out at room temperature.

\subsection{Preparation of working electrode}

Mixtures of $\mathrm{NiCl}_{2} \cdot 6 \mathrm{H}_{2} \mathrm{O}$ and graphite powder with weighting ratio of $(5: 95)$ were added to double distilled water. Then the mixture heated and stirred by a magnet to evaporate the water, after that weighting ratio $(75: 25)$ of it and mineral oil was blended by hand mixing with a mortar and pestle for preparation of carbon paste. The resulting paste was then inserted in the bottom of a glass tube (with the area of $0.07 \mathrm{~cm}^{2}$ ). The electrical connection was implemented by a copper wire lead fitted into the glass tube. A fresh electrode surface was generated rapidly by extruding a small plug of the paste with a stainless-still rod and smoothing the resulting surface on white paper until a smooth shiny surface was observed.

\section{Results and discussion}

The XRD pattern of graphite and NCMCPE is shown in Fig. 1. As clearly seen, the existence of diffraction peaks at $2 \theta$ values 53.45 and 62.90 corresponding to nickel chloride. The sharp peaks in $2 \theta=28$ is attributed to carbon base electrode. Fig. 2(a) shows the cyclic voltammograms (CVs) of the carbon paste electrode (CPE), CPE with $\mathrm{NiCl}_{2}$ / $6 \mathrm{H}_{2} \mathrm{O}$ (Fig. 2(b)) and NCMCPE (Fig. 2(c)), at the potential sweep rate of $10 \mathrm{mV} / \mathrm{s}$ in $1 \mathrm{M} \mathrm{NaOH}$ solution in the range of $0-750 \mathrm{mV}(\mathrm{Ag} / \mathrm{AgCl})$. Modification process was done by 50 consecutive cycles with scan sweep rate of $100 \mathrm{mV} / \mathrm{s}$ in $1 \mathrm{M}$ $\mathrm{NaOH}$ solution. As can be seen, no peak is

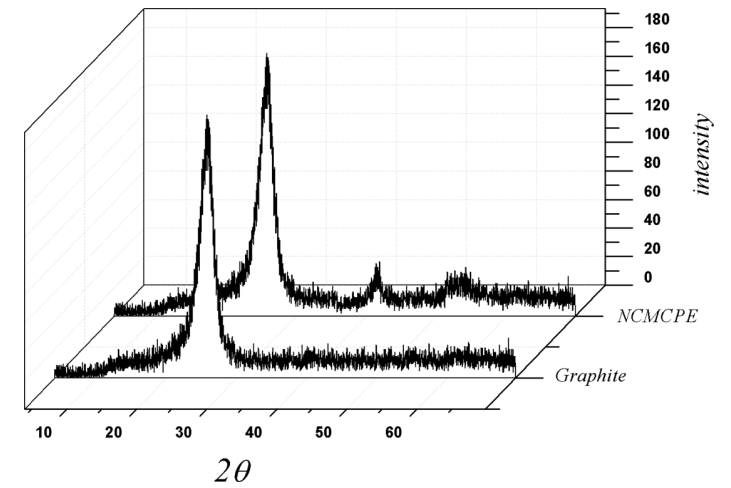

Fig. 1. XRD pattern of the $\mathrm{G}$ and NCMCPE electrodes.

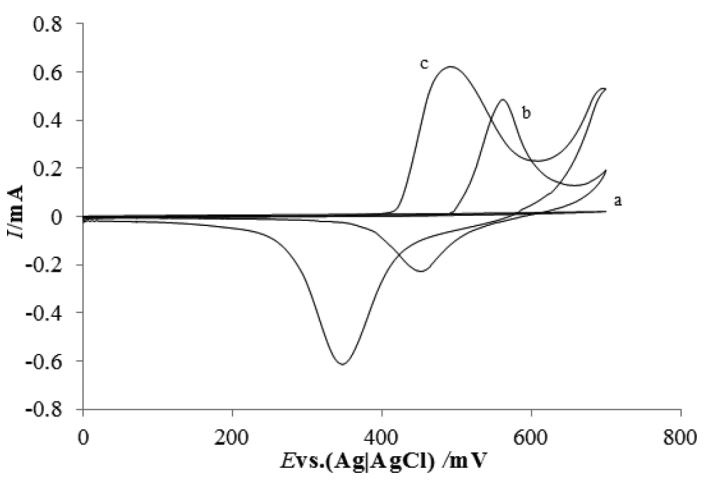

Fig. 2. Cyclic voltammograms of CPE in the absence of $\mathrm{NiCl}_{2} .6 \mathrm{H}_{2} \mathrm{O}$ (a) and with $\mathrm{NiCl}_{2} \cdot 6 \mathrm{H}_{2} \mathrm{O} \%(\mathrm{w} / \mathrm{w})$ before modification (b) and after 50 cycles by scan rate of $10 \mathrm{mV} / \mathrm{s}$ in $1 \mathrm{M} \mathrm{NaOH}$ solution. 
observed in the absence of $\mathrm{NiCl}_{2} \cdot 6 \mathrm{H}_{2} \mathrm{O}$ and by presence of $\mathrm{NiCl}_{2} \cdot 6 \mathrm{H}_{2} \mathrm{O}$ two redox peaks were appeared at 560 and $470 \mathrm{mV}(\mathrm{Ag} / \mathrm{AgCl})$ that are related to $\mathrm{Ni}^{2+} / \mathrm{Ni}^{3+}$ reactions (Fig. 2(b)) that are enhanced up on an increasing the Nickel salt. These redox peaks after modification were shifted respectively to 500 and $360 \mathrm{mV}$, pointing to higher energies (potential) required for nucleation of $\mathrm{NiOOH}$ in the first cycle. The entire behavior is in accordance with the data reported previously in the literature concerning the formation and inter-conversion of $\alpha$ - and $\beta$-phases of $\mathrm{Ni}(\mathrm{OH})_{2}$, its conversion to $\mathrm{NiOOH}$ and the enrichment of $\mathrm{Ni}^{3+}$ species on or just beneath the surface. The changes of the peak's position are likely due to the changes in the crystal structures of the nickel hydroxide and the nickel oxyhydroxide constituents of the electro-chemically formed surface film. ${ }^{26)}$ In previous work, ${ }^{4)}$ an enhanced base line current is shown in the first cycle due to $\mathrm{Ni}$ to $\mathrm{Ni}^{2+}$ oxidation, but now we already have $\mathrm{Ni}^{2+}$ species and that phenomenon does not appear. Fig. 3(a) shows the CV of NCM$\mathrm{CPE}$ in $1 \mathrm{M} \mathrm{NaOH}$ solution at various potential sweep rates of $2-750 \mathrm{mV} \mathrm{s}^{-1}$. As can be seen, when the scan rate increases the anodic peak potentials shift to more positive and the cathodic peak potentials are slightly shifted toward cathodic direction.

Fig. 3(b,c) (inset) present the plot of anodic and cathodic peaks current against potential sweep rate at low values from $2-20 \mathrm{mV} \mathrm{s}^{-1}$. Fig. 3(d,e) point to the electrochemical activity of the surface redox couple. ${ }^{27)}$ By using following equation:

$$
I_{p}=\left(\frac{n^{2} F^{2}}{4 R T}\right) v A \Gamma^{*}
$$

where $\Gamma^{*}$ is the surface coverage of the redox species and $v$ being the potential sweep rate taking average of both cathodic and anodic results, $\Gamma^{*}$ values of around $8.5 \times 10^{-7} \mathrm{~mol} \mathrm{~cm}^{-2}$ have been derived that is one order more than that of $\mathrm{Ni}$ electrode. ${ }^{16)}$ The results shows the carbon paste improve the capability of nickel to produce monolayers. Fig. 4(a) presents CVs of NCMCPE and $\mathrm{NiCl}_{2}$ in $1 \mathrm{M} \mathrm{NaOH}$ in the presence of the methanol. Fig. 4(b) Presents CVs of NCMCPE in $1 \mathrm{M}$ $\mathrm{NaOH}$ at various methanol concentrations. With increasing methanol concentration, the cathodic peaks in the reverse cycle diminishes signifying a relation between methanol oxidation and the redox process involving Ni (III) / Ni (II) species.

As can be seen, in Fig. 4 the electro catalytic oxidation of methanol occurs only in the anodic and don't continues in the initial stage of the cathodic half cycle. This can be attributed to adsorption of oxidation products on the electrode surface that prohibit the oxidation to continue. Although this desorption still occurs at low methanol concentrations, some numbers of $\mathrm{Ni}^{+3}$ sites are free and oxidation continues. The plot of peak current vs. concentration is shown in Fig. 4(b) where

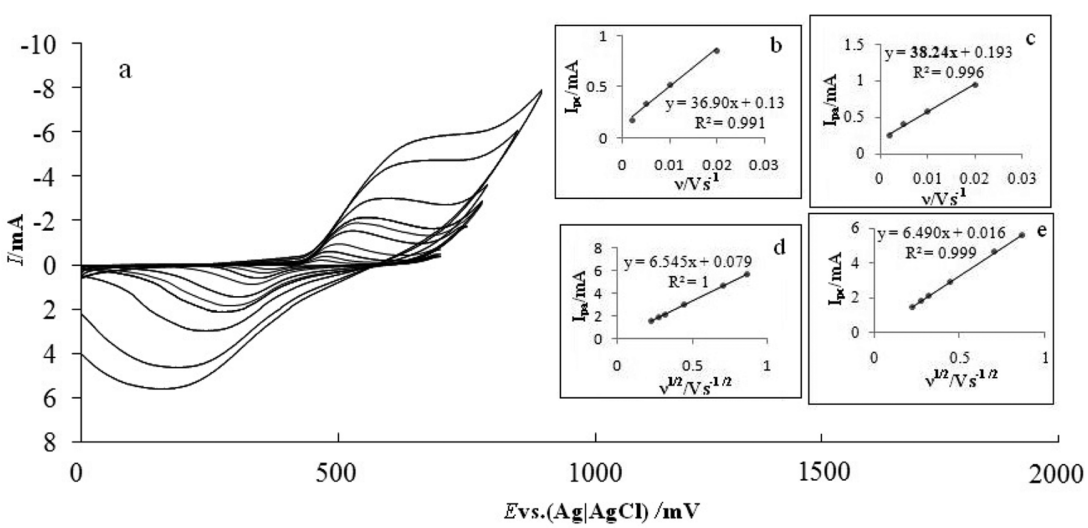

Fig. 3. (a)Typical cyclic voltammograms of a NCMCPE in $1 \mathrm{M} \mathrm{NaOH}$ in the potential sweep rates of 2, 5, 10, 20, 50, 75, $100,200,500,750 \mathrm{mVs}^{-1}$, (b) the dependency of anodic and (c) cathodic peak currents to the sweep rate at lower values $\left(2-20 \mathrm{mVs}^{-1}\right)$. (d) The proportionality of anodic and (e) cathodic peak currents to the square roots of sweep rate at higher values $(20-750 \mathrm{mV} / \mathrm{s})$. 

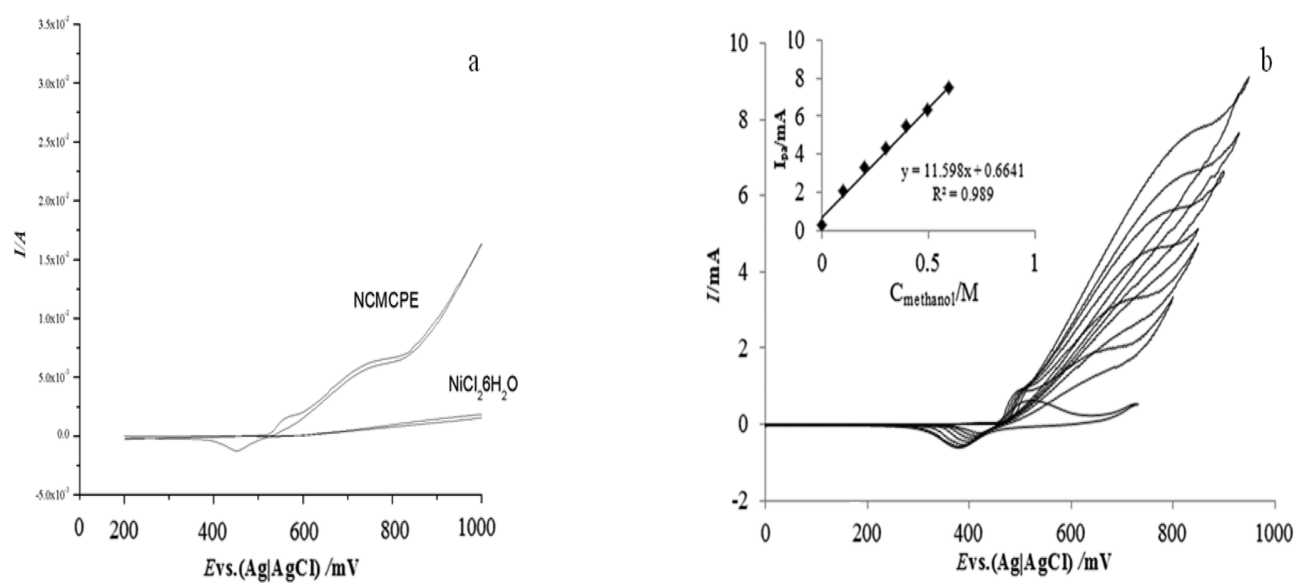

Fig. 4. (a)Comparable cyclic voltammograms of $\mathrm{NiCl}_{2}$ and $\mathrm{NCMCPE}$ electrode in $1 \mathrm{M} \mathrm{NaOH}$ solution in the presence of the methanol and (b) cyclic voltammograms of NCMCPE electrode in $1 \mathrm{M} \mathrm{NaOH}$ solution with different concentrations of methanol of: (1) $0.1 \mathrm{M}$, (2) $0.2 \mathrm{M}$, (3) $0.3 \mathrm{M}$, (4) 0.4, (5) 0.5, (6) $0.6 \mathrm{M}$ Methanol In Scan rate $10 \mathrm{mV} / \mathrm{s}$. inset d shows ependency of the anodic peak current on the concentration of methanol in solution.

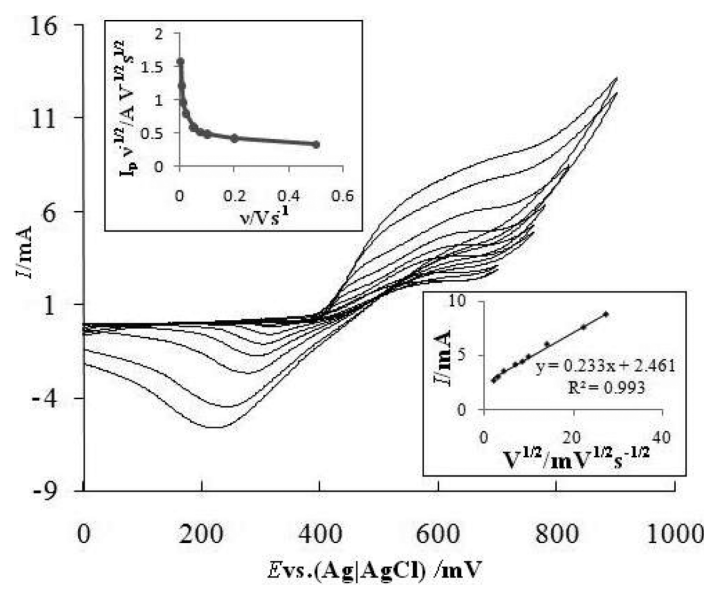

Fig. 5. (a) Typical cyclic voltammograms of the NCMCPE in $1 \mathrm{M} \mathrm{NaOH}$ in the presence of $0.3 \mathrm{M}$ methanol at various scan rate: $2,5,10,20,50,75,100,200,500,750$ and $\mathrm{mV} / \mathrm{s}$. (b) Dependence of anodic peak current during the forward sweep on the square roots of sweep rate. (c) The anodic current function $\left(\mathrm{I} / \mathrm{v}^{1 / 2}\right)$ vs. potential sweep rate $\mathrm{V} / \mathrm{s}$.

the linear dependency of current peak and methanol concentration extends up to the concentration of $0.6 \mathrm{M}$ methanol. Methanol oxidation in $1 \mathrm{M} \mathrm{NaOH}$ solution at $0.3 \mathrm{M}$ methanol concentration at various potential sweep rates from 2 to $750 \mathrm{mV} \mathrm{s}^{-1}$ is shown in Fig. 5(a). The pattern indicates that the rate of $\mathrm{Ni}$ (III) / $\mathrm{Ni}$ (II) redox processes far exceeds the rate of methanol oxidation. Also, plot of $\left(\mathrm{I}_{\mathrm{p}} / v^{1 / 2}\right)$ against the potential sweep rate $(v)$ which presented in Fig. 5(b) point to the dominance of an $\mathrm{EC}^{\prime}$ process. ${ }^{21}$

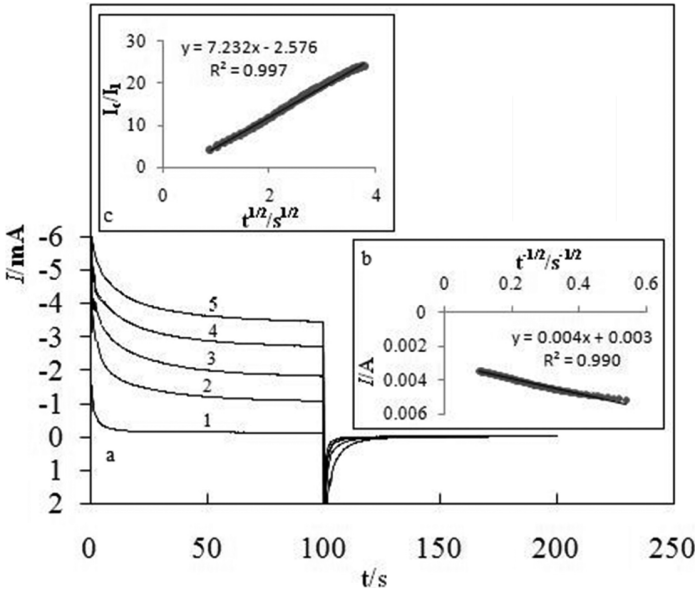

Fig. 6. (a) Double steps chronoamperogams of NCMCPE electrode in $1 \mathrm{M} \mathrm{NaOH}$ solution with different concentrations of methanol of: (1) $0 \mathrm{M}$, (2) $0.1 \mathrm{M}$, (3) $0.2 \mathrm{M}$, (4) $0.3 \mathrm{M}$, (5) 0.4 M methanol. Potential steps were $650 \mathrm{mVand} 300 \mathrm{mV}$, respectively. Inset (C) dependence of current (3) on $t^{-1 / 2}$ derived from the data of chronoamperogams of (a) in the main panel. Inset (B) dependence of $I_{C} / I_{L}$ on $t^{1 / 2}$ derived from the data of chronoamperogams of (a) and (f) in the main panel.

Meanwhile, the anodic peak currents that are linearly proportional to the square root of scan rate (Fig. 5(c)) suggest that the overall oxidation of methanol at this electrode is controlled by the diffusion of methanol from solution to the surface redox sites. Double potential step chronoamperometry was also employed to investigate the electrochemical processes. Fig. 6(a) shows the double-step 
chronoamperograms for the modified electrode by setting the working electrode potential at $650 \mathrm{mV}$ (first step) and $300 \mathrm{mV}$ (second step) for various concentrations of Methanol. The forward and reverse potential step chronoamperometry of the modified electrode in the blank solution showed an almost symmetrical chronoamperograms with almost equal charges consumed for the oxidation and reduction of surface confined $\mathrm{Ni}$ (II)/ $\mathrm{Ni}$ (III) sites. In the presence of methanol the anodic charge in forward step grows and the charge values associated with the forward chronoamperometry is larger than that observed for the reverse chronoamperograms (Fig. 6(a) (2)). The current is negligible when potential is stopped down to $300 \mathrm{mV}$, indicating that the electro catalytic oxidation of methanol is irreversible. Also, chronoamperometry used for the evaluation of the rate of the chemical reaction between the methanol and modified layer $(\mathrm{k})$ according to:

$$
I_{c} / I_{L}=\gamma\left[\pi^{1 / 2} \operatorname{erf}\left(\gamma^{1 / 2}\right)+\exp (-\gamma) / \gamma^{1 / 2}\right]
$$

Where $I_{C}$ and $I_{L}$ are the currents in the presence and absence of methanol, and $\gamma=\mathrm{kct}$ is the argument of the error function, $\mathrm{k}$ is the catalytic rate constant, $\mathrm{C}$ is bulk concentration of methanol and $\mathrm{t}$ is the elapsed time. In the cases where $\gamma>1.5$, erf $\left(\gamma^{1 / 2}\right)$ is almost equal to unity and the above equation can be reduced to ${ }^{19)}$.

$$
I_{c} / I_{L}=\gamma^{1 / 2} \pi^{1 / 2}=\gamma^{1 / 2}(\mathrm{kct})^{1 / 2}
$$

From the slope of the $I_{C} / I_{L}$ versus $\mathrm{t}^{1 / 2}$ plot, presented in Fig. 6c, the mean value of $\mathrm{k}$ for the concentration range of 0.1 to $0.4 \mathrm{M}$ of methanol was obtained as $1.4 \times 10^{4} \mathrm{~cm}^{3} \mathrm{~mol}^{-1} \mathrm{~s}^{-1}$. Furthermore, with this method we can obtain the diffusion coefficient according to ${ }^{19)}$ :

$$
I=n F A D^{1 / 2} C^{-1 / 2} t^{-1 / 2}
$$

Using the slope of $I$ against $t^{-1 / 2}$, Fig. 5(b) shows the plot of $\mathrm{I}$ vs.t $\mathrm{t}^{-1 / 2}$ with this data $\mathrm{D}$ was obtained as $3 \times 10^{-6} \mathrm{~cm}^{2} \mathrm{~s}^{-1}$.

According to our previous works ${ }^{28-35)}$ EIS have been employed in this work for presenting kinetic

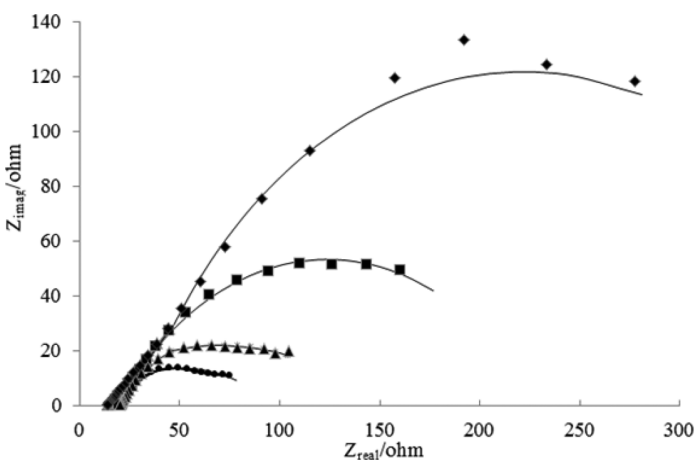

Fig. 7. Nyquist diagrams of NCMCPE electrode in different concentration of methanol in $1 \mathrm{MNaOH}$ : (1) $0.1 \mathrm{M}$, (2) $0.2 \mathrm{M}$, (3) $0.3 \mathrm{M}$, (4)0.4 M. DC potential is $650 \mathrm{mV}(\mathrm{Ag}-\mathrm{AgCl})$.

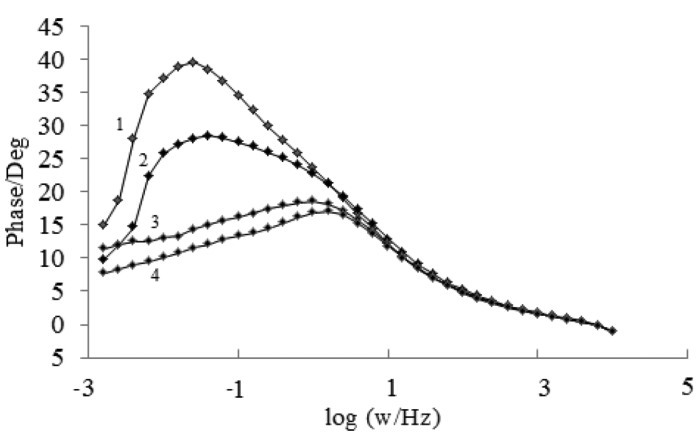

Fig. 8. phase shift plot of NCMCPE electrode in different concentration of methanol in $1 \mathrm{MNaOH}$ : (1) $0.1 \mathrm{M}$, (2) 0.2 $\mathrm{M,} \mathrm{(3)} \mathrm{0.3} \mathrm{M,} \mathrm{(4)} \mathrm{0.4} \mathrm{M.} \mathrm{DC} \mathrm{potential} \mathrm{is} 650 \mathrm{mV} / \mathrm{Ag}-\mathrm{AgCl}$.

parameters concerning methanol oxidation. Fig. 7 presents Nyquist diagrams of NCMCPE at the different concentrations of methanol in solution of $\mathrm{NaOH} 1 \mathrm{M}$. Dc potential is $650 \mathrm{mV}$. As can be seen in this figure, two depressed semi-circles in the low and high frequency sides are witnessed. By the increasing of methanol concentration the diameter of two semi-circles is decreased. The semi-circle in high frequencies can be attributed to the combination of charge transfer reaction resistance in electrooxidation of methanol and double layer capacitance. The depressed semi-circle in low frequencies is related to the adsorption of reaction intermediate on the electrode surface. Bode phase plots for the same system are shown in Fig. 8, two distinguishable Peaks are observed in the Bode plots corresponding to two depressed semicircles in the Nyquist plot. 


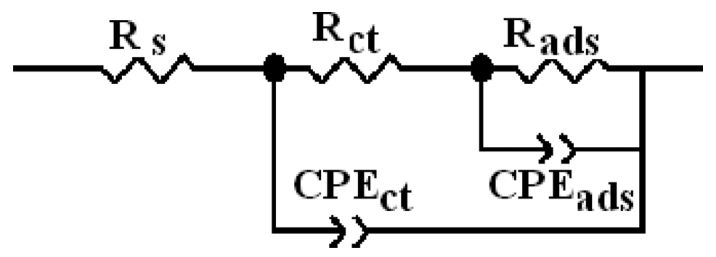

Fig. 9. Equivalent circuits compatible with the Nyquist diagrams in Fig. 6.

The equivalent circuit compatible with the Nyquist diagrams is presented in Fig. 9 that Rs, $\mathrm{CPE}_{\mathrm{dl}}, \mathrm{R}_{\mathrm{ct}}$, represents solution resistance, double layer constant phase element, charge transfer resistance and $\mathrm{R}_{\mathrm{ads}}, \mathrm{CPE}_{\mathrm{ads}}$ are related to adsorption resistance of methanol at the electrode surface and constant phase element for adsorption of methanol.

Table 1. Presents the values of the equivalent circuit elements obtained by fitting the experimental results to the equivalent circuit. These results are useful for the estimation of kinetic parameters.

On the basis of our study that is consistent with the literature, ${ }^{36-41)}$ the following mechanism is proposed for the electro-oxidation of methanol on NCMCPE and the corresponding kinetics is formulated. The electro oxidation of $\mathrm{Ni}^{+2}$ ion in the potential window:

$$
N i(\mathrm{II}) \stackrel{v_{1}}{\leftrightarrow} N i(\mathrm{III})+e^{-}
$$

Is followed by oxidation of methanol:

$$
N i(\mathrm{III})+\text { methanol } \stackrel{v_{2}}{\leftrightarrow} N i(\mathrm{II})+\text { intermediate }
$$

Where the intermediate is further oxidized to the products, format or carbonate, through similar mediated electro oxidation process:

$$
\mathrm{Ni}^{3+}+\text { intermediate } \stackrel{v_{3}}{\leftrightarrow} \mathrm{Ni}^{2+}+\text { products }
$$

In the above sequence of reactions, $\mathrm{k}_{1}$ and $\mathrm{k}_{-1}$ are obviously potential dependent and are of the forms:

$$
\begin{aligned}
& k_{1}(E)=k_{1}^{0} \exp \left[\frac{\alpha n f\left(E-E^{0}\right)}{R T}\right] \\
& k_{-1}(E)=k_{-1}^{0} \exp \left[\frac{(\alpha-1) n f\left(E-E^{0}\right)}{\mathrm{RT}}\right]
\end{aligned}
$$

Where $\mathrm{k}^{0}$ s $\mathrm{s}$ are the chemical rate constants measured at $\left(E-E^{0}\right) / \mathrm{Ag}, \mathrm{AgCl}=0, \alpha$ being the anodic symmetry factor and other parameters have their usual meanings.

The rate laws for the reactions 1 and 2 have the forms of:

$$
\begin{aligned}
& v_{1}=k_{1} \Gamma \theta_{\mathrm{II}}-k_{-1} \Gamma \theta_{\mathrm{III}} \\
& v_{2}=k_{2} \Gamma \theta_{\mathrm{III}} C_{m}
\end{aligned}
$$

Where $\Gamma$ is the total number of adsorption sites per unit area of the electrode surface, $\theta$ 's represent the fractional coverage's of different nickel valence states and $C_{m}$ is the bulk concentration of methanol. With only the (II) and (III) valence states of nickel prevailing:

$$
\theta_{\mathrm{II}}+\theta_{\mathrm{III}}=1
$$

And the rates of changes of their coverage's as well as that of the intermediate compounds being:

$$
\begin{aligned}
& \begin{aligned}
\frac{d \theta_{\mathrm{II}}}{d t} & =-\frac{d \theta_{\mathrm{III}}}{d t} \\
& =-k_{1} \theta_{\mathrm{II}}+k_{-1} \theta_{\mathrm{III}}+k_{2} \theta_{I I I} C_{m}+k_{3} \theta_{I I I} C_{i}
\end{aligned} \\
& \frac{d C_{i}}{d t}=k_{2} \theta_{\mathrm{III}} C_{m}-k_{3} \theta_{\mathrm{III}} C_{i}
\end{aligned}
$$

Where $C_{i}$ is the concentration of intermediate. Assuming that the steady state approximations dominating:

$$
\frac{d \theta_{\mathrm{II}}}{d t}=-\frac{d \theta_{\mathrm{III}}}{d t}=0
$$

Table 1. The values of the elements in equivalent circuit 1 fitted in the Nyquist plots of fig. 6.

\begin{tabular}{cccccccc}
\hline $\mathrm{n}_{2}$ & $\mathrm{n}_{1}$ & $\mathrm{Q}_{\mathrm{ads}}\left(\mathrm{F} \times 10^{-3}\right)$ & $\mathrm{Q}_{\mathrm{dl}}\left(\mathrm{F} \times 10^{-3}\right)$ & $\mathrm{R}_{\mathrm{ads}}(\Omega)$ & $\mathrm{R}_{\mathrm{ct}}(\Omega)$ & $\mathrm{R}_{\mathrm{s}}(\Omega)$ & $\mathrm{C}_{\text {methanol }}(\mathrm{M})$ \\
\hline 0.54 & 0.75 & 1.7 & 5 & 580 & 64.5 & 14.3 & 0.1 \\
0.52 & 0.56 & 2.8 & 4.8 & 180 & 51 & 14.3 & 0.2 \\
0.53 & 0.55 & 3.3 & 4.5 & 66 & 48 & 14.5 & 0.3 \\
0.55 & 0.55 & 5.2 & 4.2 & 43 & 45 & 14.5 & 0.4 \\
\hline
\end{tabular}




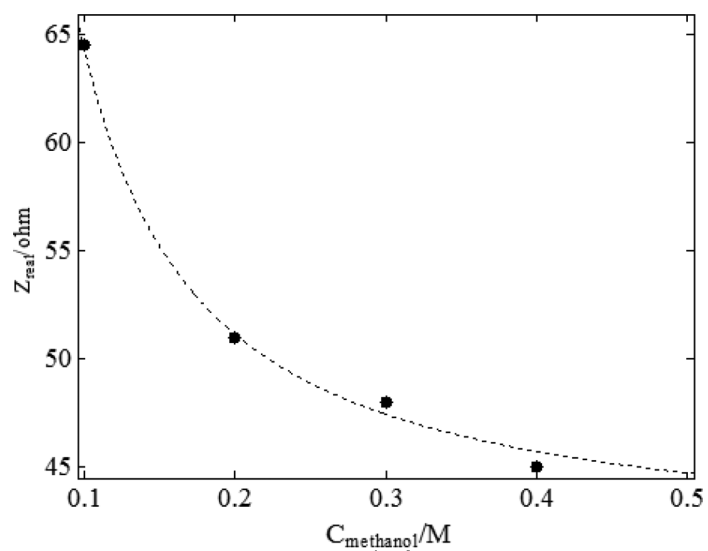

Fig. 10. Dependence of experimental Ret $(\bullet)$ on methanol concentration derived from the data of Nyquist diagrams in Fig. 6 and theoretical curve (---) on the basis Eq 17.

$$
\frac{d C_{i}}{d t}=0
$$

One arrives at the values of the overages:

$$
\begin{aligned}
& \theta_{\mathrm{II}}=\frac{\left(k_{-1}+2 k_{2} C_{m}\right)}{\left(k_{1}+k_{-1}+2 k_{2} C_{m}\right)} \\
& \theta_{\mathrm{III}}=\frac{k_{1}}{\left(k_{1}+k_{-1}+2 k_{2} C_{m}\right)}
\end{aligned}
$$

And subsequently:

$$
v_{1}=\frac{2 k_{1} \Gamma k_{2} C_{m}}{\left(k_{1}+k_{-1}+2 k_{2} C_{m}\right)}
$$

On the basis of this rate equation the faradic current will be:

$$
i_{f}=\frac{2 F A k_{1} C_{m}}{\left(k_{1}+k_{-1}+2 k_{2}+C_{m}\right)}
$$

Where A being the surface area of the electrode and the corresponding charge transfer resistance is:

$$
R_{c t}=\left(\frac{d i_{f}}{d E}\right)^{-1}=\frac{\left(k_{1}+k_{2}+2 k_{2} C_{m}^{2}\right)}{\left[2 F A \Gamma k_{2} C_{m} k_{1}\left(\frac{2 \alpha F k_{2} C_{m}}{R T}+\frac{k_{-1} F}{R T}\right)\right]}
$$

This last equation is well suited for the calculation of the rate constants and the validity test of the kinetics and the mechanism. The methanol concentrations dependency of Rct is presented in Fig. 10 when an initial sharp drop is terminated to very slow changes as the concentration of methanol is increased above $0.4 \mathrm{M}$. The results are fitted in Eq.

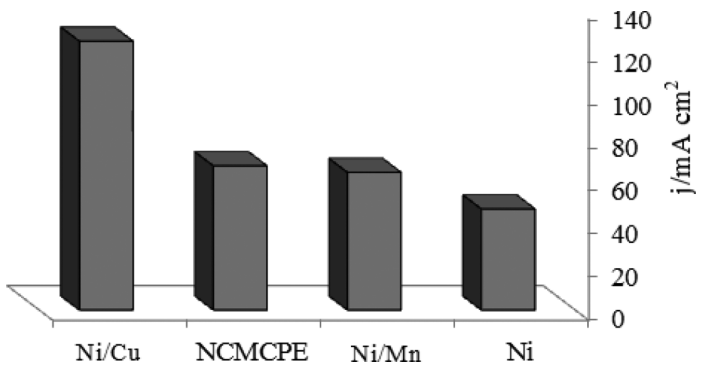

Fig. 11. Current density of some electrodes for oxidation of methanol in same concentration for compare with NCMCPE.

20 and the and the rate constant values were calculated as $\mathrm{k}_{1}=2.3 \times 10^{-7} \mathrm{~S}^{-1}, \mathrm{k}^{-1}=3 \times 10^{-9} \mathrm{~S}^{-1}$ and $\mathrm{k}_{2}=2.6 \times 10^{3} \mathrm{~cm}^{3} \mathrm{~mol}^{-1} \mathrm{~S}^{-1}$ have been calculated.

Fig. 11 shows the current density of some electrodes for oxidation of methanol in same concentration with compared to NCMCPE. It is apparent that by using this electrode the electro catalytic activity of nickel enhanced because by use of only $5 \%$ nickel in the electrode, the current density is more than $\mathrm{Ni} / \mathrm{Mn}$ electrode and also $\mathrm{Ni}$ electrode that all the surface of electrode is $\mathrm{Ni}$ atoms. The results show that, the NCMCPE has better catalytic performance. This is mainly because of the really large surface area, and the better electronic and ionic conductivity of NCMCPE.

\section{Conclusion}

This work presents the preparation and usefulness of nickel hydroxide (oxide) modified carbon paste electrodes for methanol electro-oxidation in alkaline media. The electrode was electro-catalytically active around $650 \mathrm{mV}(\mathrm{Ag} / \mathrm{AgCl})$ where the $\mathrm{CPE}$ electrode possessed no activity. A kinetic model was developed and the kinetic parameters were calculated using the methanol concentration dependency of charge transfer resistance derived from the impedance studies.

\section{References}

1. G. Cacciola, Antonucci V., and Freni S., J. Power Sources, 100, 67 (2001).

2. J. M. Andu' jar and F. Segura, Renew Sust Energ Rev, 13, 2309 (2009).

3. J. Ge and H. Liu, J. Power Sources, 142, 56 (2005). 
4. I. Danaee, M. Jafarian, A. Mirzapoor, F. Gobal, M. G. Mahjani, Electrochim Acta, 55, 2093 (2010).

5. G. Orozco, M. C. Pérez, A. Rincón, and C. Gutiérrez, (2000) J. Electro Anal Chem, 495, 71 (2000).

6. L. Jiang, A. Hsu, D. Chu, and R. Chen, Int J. Hydrogen Energ 35, 365 (2010).

7. Xu Yuan hang, A. Amini, and M. Schell, J. Electroanal Chem, 398, 95 (1995).

8. S. Berchmans, H. Gomathi, and G. PrabhakaraRao, $J$. Electroanal Chem, 394, 267 (1995).

9. F. Vogel, J. L. DiNaro Blanchard, P. A. Marrone, S. F. Rice, P. A. Webley, W. A. Peters, K. A. Smith, J. W. Tester, J. Supercrit Fluid, 34, 249 (2005).

10. I. Becerýk, S. Süzer, and F. Kadirgan, J. Electroanal Chem 502:118 (2001).

11. T. Okada, Arimuran, C. Ono, and M. Yuasa, Electrochim Acta, 51, 1130 (2005).

12. H. Heli, M. Jafarian, M. G. Mahjani, and F. Gobal F, Electrochim Acta, 49, 4999 (2004).

13. A. Aramata and W. Veerasai, Electrochim Acta, 36, 1043 (1991).

14. C. H. Lee, C. W. Lee, D. I. Kim, D. H. Jung, C. S. Kim, and D. RyulShin, J. Power Sources, 86, 478 (2000).

15. W. Tokarz, H. Siwek, P. Piela, and A. Czerwinsky, Electrochim Acta, 52, 5565 (2007).

16. I. Danaee, M. Jafarian, F. Forouzandeh, F. Gobal, and M. G. Mahjani, Int. J. Hydrogen Energ, 34, 859 (2009).

17. M. A. Abdel Rahim, R. M. Abdel Hameed, and M. W. Khalil, J. Power Sources, 134, 160 (2004).

18. A. Nozad Golikand, M. Asgari, M. Ghannadi Maragheh, and S. Shahrokhian, J. Electroanal Chem, 588, 155 (2006).

19. J. Raoof, A. Omrani, R. Ojani, and F. Monfared, J. Electroanal Chem, 633, 153 (2009).

20. R. Ojani, J. Raoof, and S. Fathi, J. Solid State Electr, 13, 927 (2009).

21. R. Ojani, J. Raoof, and P. Salmany-Afagh, J. Electroanal Chem, 571, 1 (2004).

22. J. Taraszewska and G. Roslonek, J. Electroanal Chem, 364, 209 (1994).
23. R. M. Van Effen and D. H Evans, J. Electroanal Chem., 103, 383 (1979).

24. A. J. Motheo, S. A. S. Machado, F. J. B. Rabelo, and Jr. Santos, J. Brazil Chim Soc, 5,161 (1994).

25. M. Fleischmann, K. Korinek, and D. Pletcher, J. Electroanal Chem, 31, 39 (1971).

26. A. A. El-Shafei, J. Electroanal Chem., 471, 89 (1999).

27. A. Hamnett, CATAL TODAY, 38, 445 (1997).

28. A. Ehsani, B. Jaleh, and M. Nasrollahzadeh, J. Power Sources, 257, 300 (2014).

29. M. Nasrollahzadeh, A. Ehsani, A. Rostami-Vartouni, Ultrasound Sonochem, 21, 275 (2014).

30. A. Ehsani, F. Babaei, and M. Nasrollahzadeh, Applied Surface Science, 283, 1060 (2013).

31. A. Ehsani, M. G. Mahjani, M. Bordbar, S. Adeli, J. Electroanal. Chem., 710, 29 (2013).

32. M. Mahjani, A. Ehsani, M. Jafarian, SYNTH. METH, 160, 1252 (2010).

33. A. Ehsani, M. Nasrollahzadeh, MG. Mahjani, R. Moshrefi, H. Mostaanzadeh, J. Ind. Eng. Chem, doi: 10.1016/ j.jiec.2014.01.045.

34. A. Ehsani, M. G. Mahjani, R. Moshrefi, H. Mostaanzadeh, and J. Shabani Shayeh, RSC Adv, 4, 38, 20031 20037 (2014).

35. A. Ehsani, M. G. Mahjani, and M. Jafarian, Turkish Journal of Chemistry, 35, 1 (2011).

36. A. Ehsani, M. G. Mahjani, M. Jafarian, A. Naeemy A, Progress Organic Coating, 69, 510 (2010).

37. A. Ehsani, M. G. Mahjani, and Jafarian, Synth Met., 161, 1760 (2011)

38. A. Ehsani A, M. G. Mahjani, and Jafarian (2012) Synth Met., 162, 199 (2012).

39. A. Ehsani, M. G. Mahjani, M. Jafarian, and A. Naeemy, Electrochim Acta., 71, 128 (2012).

40. A. R. Feizbakhsh, A. Naeemy, A. Ehsani, A. Aghasi, and I. Danaee, J. Chiness Chem. Soc., 59, 1086 (2012)

41. A. Ehsani, S. Adeli, F. Babaei, H. Mostaanzadeh, M. Nasrollahzadeh (2014) J. Electroanal Chem., 713, 91 (2014). 